\title{
INTEGRAÇÃO DE ATIVIDADES EXPERIMENTAIS E TECNOLOGIAS EDUCACIONAIS NO ENSINO DO CONCEITO DE pH
}

\author{
Vinícius Vendrusculo*; Carlos Alberto da Silva Mello \\ E-mail*: vinicius.vendrusculo@hotmail.com \\ Instituto Federal de Educação, Ciência e Tecnologia Sul-rio-grandense; Instituto Federal de \\ Educação, Ciência e Tecnologia de Santa Catarina
}

DOI: 10.15628/rbept.2020.9065

Artigo submetido em: out./2019 e aceito em: jul./2020

\section{RESUMO}

Na Educação Profissional, um dos grandes objetivos é a preparação para o mundo do trabalho, através da utilização de práticas pedagógicas inseridas na área de formação do curso. Este trabalho descreve uma abordagem híbrida que utiliza tecnologias e experimentação, realizada junto a estudantes do $1 \stackrel{0}{ }$ ano do ensino médio integrado - técnico em informática a respeito do tema: ácidos, bases e pH. Buscou-se a construção de uma escala de pH utilizando-se diferentes substâncias e um aplicativo para leitura de cores. Notou-se um bom envolvimento dos alunos, que demonstraram curiosidade e participação nos experimentos. $O$ uso do aplicativo e de planilhas eletrônicas auxiliou na aproximação da prática com a área de formação técnica do curso, sendo a atividade avaliada positivamente pelos alunos.

Palavras-Chave: Experimentação. Tecnologias educacionais. Ensino de química.

\section{INTEGRATION OF EXPERIMENTAL AND TECHNOLOGICAL EDUCATIONAL ACTIVITIES IN TEACHING OF PH CONCEPT}

\begin{abstract}
On the technician education, one of the most important goals is the qualification for the job market through the use of pedagogic practices that are in agreement with the work area. This work describes an hybrid approach that uses laboratory experimentation and educational technologies with junior high school students of a computer technician course at the topic: acids, bases and $\mathrm{pH}$. It was tryed to build a pH scale using different substances and a color reading app. It was noticed a good interest of the students with curiosity and participation on the activitie. The use of the app, together with a shared worksheet construction tool provided the approximation with the field of work of the course, and the activity has been well evaluated by the students.
\end{abstract}

Keywords: Experimentation. Educational Technologies. Chemical Education. 


\section{INTRODUÇÃO}

A Educação Profissional e Tecnológica (EPT) tem como um dos seus pilares a vivência da prática profissional aliada aos conteúdos teóricos, podendo isto ocorrer dentro ou fora da sala de aula. Segundo Wollinger (2016), atividades experimentais que possam tirar o estudante apenas do universo da abstração e inseri-lo em ambientes onde ele possa vivenciar os fenômenos estudados é uma prática que contribui para a melhora do processo de construção do conhecimento. Do ponto de vista pedagógico, as práticas de experimentação também são incentivadas uma vez que, sendo elas consideradas metodologias ativas, têm o potencial de retirar o estudante do mero papel de espectador e permiti-lo assumir o papel de protagonista no processo de ensino-aprendizagem. (ANASTASIOU; ALVES, 2004).

No ensino de química, as atividades experimentais já são práticas consagradas, uma vez que a realização de aulas práticas em laboratório é costumeiramente utilizada ao se abordar diversos conteúdos (GIORDAN, 1999). Dentre estas práticas, um experimento já descrito na literatura é a utilização de extrato de repolho roxo como indicador de $\mathrm{pH}$ (potencial hidrogeniônico) no ensino de ácidos e bases (LIMA ET AL, 1996). Entretanto, esta técnica, assim como muitas outras, apresenta uma dificuldade normalmente vivenciada nos laboratórios de química, que é a diferenciação de cores por parte dos analistas. Quando a diferenciação de cores é realizada a olho nu, é recorrente que os alunos atribuam cores diferentes para uma mesma solução, o que ocasiona erros no resultado do experimento. Além disso, esta técnica pode tornar-se inviável de ser realizada por estudantes que possuam Daltonismo, distúrbio cromático que se caracteriza por prejudicar parcial ou totalmente a capacidade de se diferenciar visualmente algumas cores. (LEE; SANTOS, 2008).

Dentro deste contexto, uma abordagem que pode auxiliar pedagogicamente é a utilização de objetos de aprendizagem que, segundo Wiley (2001), tratam-se de entidades digitas que possuem grande potencial de atuação na área da educação, de forma a despertar o interesse e engajamento de estudantes, potencializando o processo de aprendizagem. Simuladores, laboratórios virtuais, aplicativos para dispositivos móveis, ferramentas de construção compartilhada (entre outros) são boas alternativas para o uso na educação. (BACICH ET AL., 2015; MORENO E HEIDELMANN, 2017).

Sendo assim, este trabalho aborda a utilização de um aplicativo para dispositivos móveis no ensino do conceito de $\mathrm{pH}$ aos alunos do $1^{\circ}$ ano curso técnico de nível médio em informática de uma instituição pertencente à rede federal de educação profissional. Para isso, buscou-se desenvolver uma escala de $\mathrm{pH}$ utilizando um aplicativo de leitura de cores na análise das colorações do indicador ácido-base de repolho roxo em diferentes faixas de $\mathrm{pH}$. Neste processo, utilizando-se a aula experimental aliada à utilização do aplicativo de leitura de cores, buscou-se obter os dados experimentais a serem utilizados para a construção da escala de $\mathrm{pH}$ através da ferramenta de construção compartilhada "google docs". Com esta estratégia, acredita-se que seja possível aliar a experimentação e a prática profissional, tão importantes 
no contexto da EPT, à utilização de objetos de aprendizagem, a fim de se encontrar estratégias mais atrativas e didáticas para a construção dos conhecimentos sobre $\mathrm{pH}$. Outro fator relevante é a área profissional do curso, técnico em informática, pois se acredita que o uso do aplicativo será mais um fator de interesse por parte dos estudantes, já que, durante o seu curso, uma das habilidades desenvolvidas é a criação de aplicativos para dispositivos móveis.

\section{EDUCAÇÃO PROFISSIONAL E TECNOLOGICA}

Desde a criação das primeiras Escolas de Aprendizes e Artífices, em 1909, a educação profissional possui um importante papel no Brasil (PACHECO ET AL, 2009). Com a criação dos Institutos Federais, a EPT passou a ter um papel de destaque no cenário educacional nacional, motivando também diversos estudos que tratam das abordagens utilizadas na educação profissional e tecnológica. Berger Filho (1999) destaca que esta modalidade de educação visa não apenas a formação intelectual e teórica do estudante, mas busca Ihe proporcionar formação técnica prática para que possa exercer seu ofício no mundo do trabalho. Este objetivo pode ser alcançado através de diversas estratégias, dentre as quais, estão as aulas práticas, visitas técnicas, estágios, alternância, simulações, entre outros. (WOLLINGER; ALLAIN, 2017).

Dentro desta realidade teórico-prática da educação profissional, uma estratégia que pode ser muito eficaz no processo de ensino-aprendizagem é a utilização de atividades experimentais no ensino de ciências. Elas permitem ao estudante exercer um papel mais ativo na construção do conhecimento, promovendo uma maior discussão em relação aos temas, deixando o processo de aprendizagem mais natural, motivador e melhorando quantitativamente os resultados quando medido por meio de avaliações (CARDOSO, 2013).

A utilização de processos mais modernos de ensino que utilizam metodologias ativas passa também pela adaptação das estratégias em sala de aula, assim como dos ambientes escolares. A utilização de tecnologias educacionais que possam trazer interatividade é muito bem-vinda, em especial, a utilização de dispositivos móveis conectados a redes sem fio. $O$ espaço de aprendizagem deve ser ampliado, integrado, deixando-se para trás a concepção de que só se aprende dentro das quatro paredes da sala (MORAN, 2015). Desta forma, a integração entre sala de aula, tecnologias educacionais e um laboratório de atividades experimentais para o ensino de química pode ser um grande aliado na construção do conhecimento, pois irá proporcionar esta ampliação do espaço de aprendizado, integrando o conteúdo a ser trabalhado com atividades interativas e, por que não, divertidas (VENDRUSCULO; ANTUNES, 2018).

Um importante ponto a respeito da educação profissional e tecnológica é a questão de que as metodologias, ativas ou tradicionais, devem possuir proximidade com a área de formação técnica do futuro profissional, pois isso irá contribuir não apenas para a formação técnica, mas irá aumentar o interesse do estudante pelos conteúdos da formação geral (Manfredi, 2017). Neste 
sentido, a utilização de tecnologias educacionais tende a auxiliar muito no ensino de conteúdos de ciências no ensino médio técnico integrado, especialmente tratando-se de um curso técnico em informática, o qual é objeto deste estudo.

\section{METODOLOGIA}

Neste trabalho, utilizou-se uma abordagem predominantemente qualitativa, uma vez que a efetividade da abordagem foi avaliada in loco, pelas interações e reações dos estudantes, o que se acredita ser, neste caso, mais adequado às concepções de construção do conhecimento via metodologias ativas.

Para realização da atividade, o grupo de 32 estudantes foi dividido em dois subgrupos de 16 integrantes. Após esta organização, os grupos realizaram uma pesquisa sobre o tema no laboratório de informática, que se somou à realização da aula prática, totalizando 4 horas/aula envolvidas na atividade. No laboratório de química, os estudantes trabalharam em grupos contendo 4 participantes cada. Cada um dos grupos realizou a medição do $\mathrm{pH}$, via extrato aquoso de repolho roxo (LIMA ET AL, 1996), das seguintes amostras: água destilada, água com gás, refrigerante de limão, vinagre, suco de limão, leite magnésia, fermento de pão (em água), comprimido antiácido (em água), cal (em água), solução de $\mathrm{NaOH} 0,1 \mathrm{~mol} / \mathrm{L}$ e solução de $\mathrm{HCl} 0,1$ $\mathrm{mol} / \mathrm{L}$. A confirmação dos resultados foi realizada em conjunto com o professor, através da verificação das cores encontradas e de pesquisas bibliográficas. $\mathrm{Na}$ aula seguinte, foram realizadas as reflexões sobre a atividade desenvolvida.

Para a coleta de dados, utilizou-se a observação, sendo complementada com a aplicação de um questionário aos participantes. $\mathrm{O}$ questionário foi elaborado com cinco afirmativas em escala Likert de cinco pontos. Nestas afirmativas, eles deveriam expressar seu grau de concordância com cada uma delas, havendo as seguintes opções: 1 - Discordo plenamente; 2 - Discordo; 3 - Indiferente; 4 - Concordo; 5 - Concordo plenamente. Além destas, foram elaboradas ainda duas questões abertas, nas quais havia espaço para o apontamento de pontos positivos e negativos. O questionário foi respondido pelos 32 estudantes envolvidos na abordagem, tendo sido este preenchimento de forma anônima.

\section{RESULTADOS E DISCUSSÕES}

A realização da aula prática foi encarada pelos estudantes com muito entusiasmo e engajamento. O envolvimento dos mesmos com o conteúdo e os conceitos trabalhados foi muito positivo, pois eles procuravam entender o que estava ocorrendo em seus experimentos para poderem explicar posteriormente tais fenômenos. Este fato já era esperado, uma vez que diversos autores citam estes aspectos como vantagens da realização de atividades experimentais no 
ensino de química (GIORDAN, 1999). A Figura 1 mostra a realização da primeira parte da atividade por um dos grupos, para fins de ilustração.

Figura 1: realização da atividade experimental

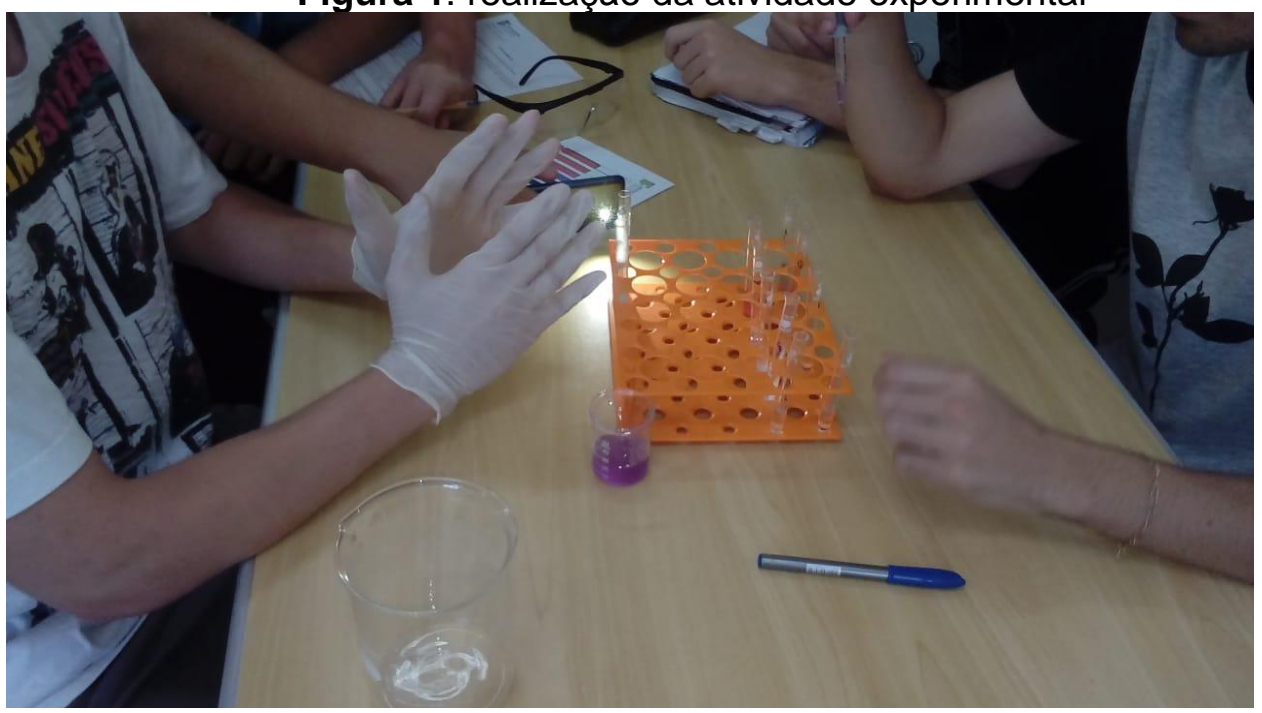

Fonte: acervo pessoal do autor (2018)

Com relação a avaliação do aprendizado, como citado anteriormente, a mesma foi estimada a partir das interações e conversas durante e após a atividade. Percebeu-se que a aprendizagem pôde ser efetiva, pois, em momentos posteriores, nos quais os estudantes pesquisavam sobre o assunto para entregarem seus relatos de experiência, não surgiram dúvidas básicas sobre os conceitos trabalhados, o que indica que tais conceitos foram entendidos e apropriados pelos estudantes. Também, ao se debater o assunto em aula, em geral, os estudantes respondiam com facilidade às perguntas relacionadas à atividade.

Em relação à utilização do aplicativo de leitura de cores, os alunos demonstraram muita pró-atividade e interesse, uma vez que praticamente todos já haviam baixado o mesmo em seus aparelhos celulares anteriormente à aula. Foi disponibilizado também um tablet com o aplicativo para grupos que eventualmente não tivessem acesso ao mesmo, sendo que apenas um dois oito grupos o utilizou, por não ter conseguido baixar o aplicativo em seus aparelhos celulares. Durante a utilização do aplicativo, não foi preciso que o professor fornecesse orientações adicionais, pois os estudantes, rapidamente, aprenderam como utilizá-lo na prática, estando este fato de acordo com as proposições que são feitas a respeito destas gerações de "nativos digitais" (PALFREY; GASSER, 2011). Outro fato a ser destacado é o de que os estudantes descobriram funcionalidades que o professor não conhecia no aplicativo, o que facilitou muito a atividade e trouxe à intervenção a tão buscada "via de mão dupla" na educação, na qual não é apenas um que aprende e outro que ensina, mas professores e estudantes crescem conjuntamente (BERBEL, 2011). Com relação à construção da escala de pH utilizando o aplicativo, não foi possível construir uma escala numérica de tons e cores, uma vez que o 
aplicativo apresentava certa sensibilidade ao ambiente (luz, cor de fundo, movimentos), o que foi percebido pelos estudantes. Porém, foi possível construir a escala utilizando as cores básicas encontradas em determinadas faixas de $\mathrm{pH}$, conseguindo-se assim, atingir o objetivo proposto e possibilitando com que um estudante portador de daltonismo, por exemplo, pudesse realizar a prática normalmente, junto dos demais. As cores encontradas por cada grupo foram lançadas em uma planilha compartilhada no google drive, e a partir desta, foi construída a escala de $\mathrm{pH}$ do extrato do repolho roxo versus cores mais detectadas via aplicativo, conforme mostrado na Figura 2.

Figura 2: Escala de $\mathrm{pH}$ a partir do indicador de extrato de repolho roxo versus cores mais detectadas via aplicativo

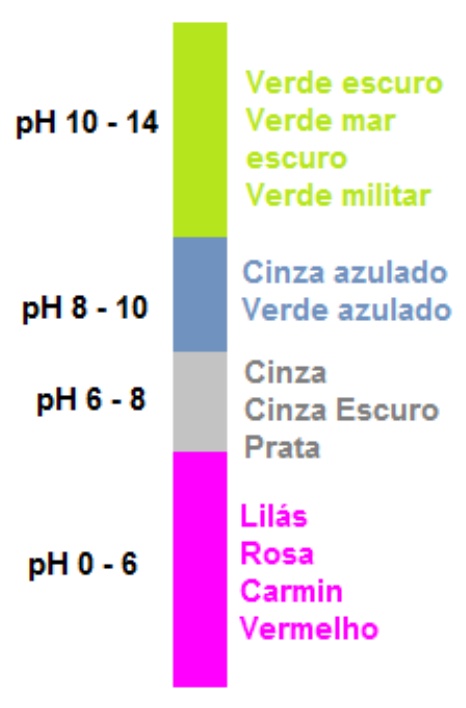

Fonte: acervo pessoal do autor (2018)

Com isso, pôde-se perceber que tanto a utilização do aplicativo, como da ferramenta de construção compartilhada, auxiliaram no envolvimento e no interesse dos estudantes pela atividade, já que os mesmos conseguiram perceber a relação das tecnologias com a sua área de formação. Ao detectarem algumas falhas no aplicativo, os estudantes também discutiram sobre a possibilidade de desenvolvimento, no futuro, de um aplicativo similar que não possuísse tais falhas e pudesse ser utilizado com mais eficiência no procedimento realizado, o que está perfeitamente alinhado com os objetivos da EPT (WOLLINGER, 2016), no que diz respeito à inserção das metodologias no ambiente profissional do futuro técnico em informática. Os estudantes também foram capazes de estabelecer as condições ideais de utilização do aplicativo, como a utilização ou não do flash do celular, e o uso de um fundo branco para melhor visualização das cores.

Em aula posterior à realização da atividade, os estudantes responderam ao questionário, que continha cinco afirmações em escala likert 
de 5 pontos: (1) A aula prática sobre $\mathrm{pH}$ no laboratório contribuiu para seu aprendizado; (2) A realização da aula prática foi positiva se comparada à maneira que normalmente se trabalha os conteúdos de química em aula; (3) Foi possível fazer a leitura das cores utilizando o aplicativo em questão; (4) Foi possível visualizar a escala de $\mathrm{pH}$ e construir uma escala de acidez das amostras com base na atividade realizada; (5) Você percebeu mais efetividade no seu aprendizado do que se tivesse sido lido o conteúdo no livro e resolvidos exercícios sobre o mesmo.

Com base nas respostas, expressas graficamente na figura 3, nota-se que nas afirmações 1, 2 e 5, mais de $90 \%$ dos estudantes (somatório das respostas concordo (C) e concordo plenamente (CP)) encararam a atividade de forma positiva, acreditando que esta abordagem contribuiu para a construção do conhecimento em relação ao tema. Na visão dos mesmos, foram obtidos ganhos em relação à tradicional metodologia expositivo-dialogada. Importante ressaltar que não se sugere com isso o banimento drástico da abordagem tradicional, mas sim uma inserção gradual, crescente e adaptativa das metodologias ativas junto aos estudantes, que tende a potencializar o processo de construção do conhecimento em sala de aula (Moran, 2015).

As questões 3 e 4 abordaram a efetivação dos objetivos da atividade prática em si. Em relação à afirmação 3, 81\% dos estudantes (somatório das respostas concordo (C) e concordo plenamente (CP)) acreditam que foi possível utilizar o aplicativo de dispositivos móveis para visualizar a escala de $\mathrm{pH}$, enquanto 19\% deles (soma das respostas I, D e DP) julgou que não foi possível. Isso provavelmente se deve ao fato de que alguns grupos tiveram dificuldades na estabilização das cores para leitura, condições de iluminação e cores de fundo. Mesmo com essas dificuldades, ao final, foi possível que a turma construísse uma escala utilizando as médias das cores mais frequentes encontradas em cada faixa de $\mathrm{pH}$. Conforme mencionado anteriormente, a ocorrência destes imprevistos suscitou nos estudantes a procura por soluções para a utilização do aplicativo durante a realização das leituras, tendo a maioria dos grupos obtido sucesso nesta tarefa, diretamente relacionada à sua área de formação técnica. Em relação à afirmação 4, 97\% (soma das respostas $\mathrm{C}$ e $\mathrm{CP}$ ) afirmaram que conseguiram construir e interpretar a escala de $\mathrm{pH}$, demonstrando que a atividade experimental realizada, além de ser interessante e produtiva, é perfeitamente factível, não apenas com a utilização do repolho roxo, mas também outros indicadores (PENAFORTE; SANTOS, 2014). 
Figura 3: Respostas dos estudantes ao questionário aplicado em escala likert de 5 pontos

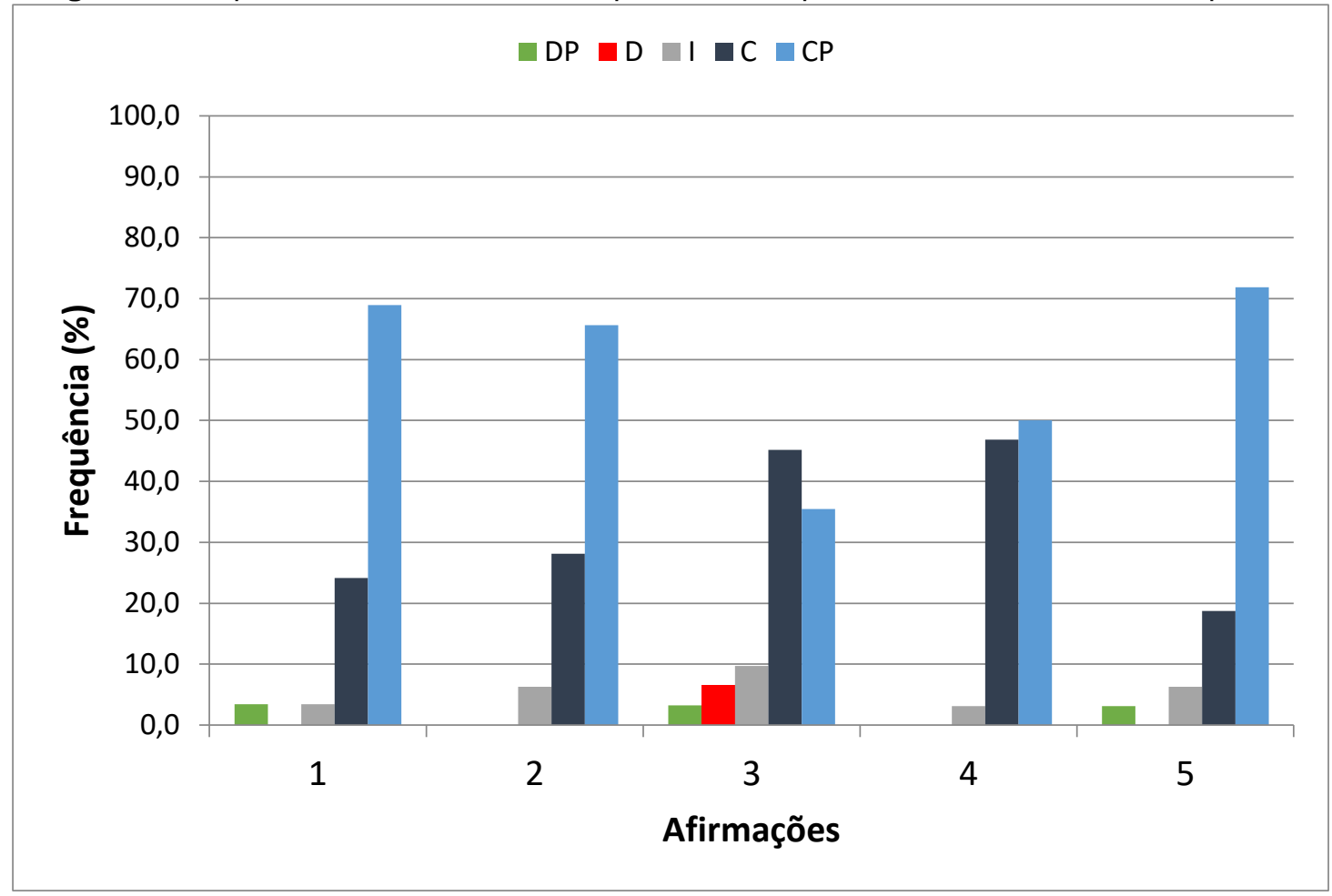

Fonte: acervo pessoal do autor (2018).

Os estudantes responderam também a duas questões abertas, sendo as seguintes: (6) "Quais os pontos mais interessantes da aula?; (7) Quais os pontos que poderiam ter sido melhores na aula?. Na questão 6 , diversas respostas similares foram recebidas, em geral, elogiando o dinamismo e ressaltando o interesse e a curiosidade despertados pela atividade. Já na questão 7 , não foi mencionada nenhuma crítica à metodologia ou ao experimento, porém, $21 \%$ dos estudantes reclamaram da postura dos próprios colegas no laboratório, cobrando mais seriedade e menos brincadeiras durante a atividade. Sabe-se que o ambiente escolar no ensino médio está sujeito a situações de falta de responsabilidade e comprometimento, porém, o amadurecimento e o crescimento do aluno fazem parte do processo, e devem ser trabalhados continuamente (TAPIA, 1999).

\section{CONSIDERAÇÕES FINAIS}

A utilização de atividades experimentais no ensino de química é uma prática usual, especialmente em cursos técnicos e cursos de graduação na área. A implementação deste tipo de abordagem na EPT em cursos de áreas diferentes da química é um desafio aos educadores. Acredita-se que a utilização de um aplicativo para dispositivos móveis aliado à atividade experimental de determinação de $\mathrm{pH}$ foi eficaz em sua tarefa de envolver a área de formação do curso técnico em informática com o conteúdo de química. 
Percebeu-se também a participação, a curiosidade e o interesse dos estudantes, quando a estratégia é comparada à abordagem tradicional. Além disso, a prática realizada abre portas para um possível processo de inclusão de estudantes portadores de daltonismo na realização de uma atividade na qual a diferenciação de cores é necessária. Já na opinião dos próprios alunos, atividades como estas são muito positivas em seu processo de aprendizado, e deveriam ser realizadas com maior frequência.

Este trabalho não tem o intuito de estabelecer conclusões definitivas sobre a utilização de experimentação (e outras metodologias ativas) aliada à tecnologia no ensino de química, uma vez que é relatada aqui apenas uma intervenção pontual utilizando tais práticas. Porém, as reflexões aqui realizadas podem contribuir para que outros pesquisadores possam encarar estratégias como esta de forma positiva, buscando a melhora contínua de suas práticas em sala de aula e o desenvolvimento de novas práticas pedagógicas.

\section{REFERÊNCIAS}

ANASTASIOU, L.G. C. ALVES, L. P. A. Estratégias de ensinagem. Processos de ensinagem na universidade. Pressupostos para as estratégias de trabalho em aula, v. 3, p. 67-100, 2004. Disponível em: $<$ https://www.ufmt.br/proeg/arquivos/2dc95cd453e52a78a17dcc157f04dbf6.pd f>. Acesso em: 20 set. 2018.

BERBEL, N. A. N. As metodologias ativas e a promoção da autonomia de estudantes. Semina: Ciências Sociais e Humanas, v. 32, n. 1, p. 25-40, 2011. Disponível em:

<http://www.uel.br/revistas/uel/index.php/seminasoc/article/view/10326>. Acesso em: 04 out. 2018.

BERGER FILHO, R. L. Educação profissional no Brasil: novos rumos. Revista Iberoamericana de educación, n. 20, p. 87-105, 1999. Disponível em: < https://rieoei.org/historico/documentos/rie20a03.PDF>. Acesso em: 20 set. 2018.

CARDOSO, F. O uso de atividades práticas no ensino de ciências: na busca de melhores resultados no processo ensino aprendizagem. Trabalho de Conclusão de Curso (Graduação em Licenciatura de Ciências Biológicas). Centro Universitário Univates, Lajeado, 2013. Disponível em: <https://m.univates.br/bdu/handle/10737/380>. Acesso em: 07 nov. 2018.

DE LIMA, V. A.; BATTAGGIA, M; GUARACHO, A. e INFANTE, A.

Demonstração do efeito tampão de comprimidos efervescentes com extrato de repolho roxo. Química Nova na Escola, n.1, p. 33-34, 1995. Disponível em: < http://qnesc.sbq.org.br/online/qnesc01/exper2.pdf>. Acesso em: 16 ago. 2018.

GIORDAN, M. O papel da experimentação no ensino de ciências. II Encontro 
Nacional de Pesquisa em Educação em Ciências, Valinhos, 1999.

Disponível em:

<http://abrapecnet.org.br/atas_enpec/iienpec/Dados/trabalhos/A33.pdf>. Acesso em: 07 nov. 2018.

LEE, J. e SANTOS, W. P. Uma Ferramenta Adaptativa para Facilitar a Visualização de Imagens para Pessoas Portadoras de Daltonismo. In: $21^{\circ}$ Congresso Brasileiro de Engenharia Biomédica, Salvador, 2008. Anais... Disponível em: http://www.sbeb.org.br/site/wpcontent/uploads/XXICBEB2008-Vol1.pdf . Acesso em 23 abr. 2019.

MANFREDI, S. M. Educação profissional no Brasil: atores e cenários ao longo da história. Jundiaí: Paco Editorial, 2017.

MORAN, J. Mudando a educação com metodologias ativas. Coleção Mídias Contemporâneas. Convergências Midiáticas, Educação e Cidadania: aproximações jovens. Ponta Grossa: Foca Foto-PROEX/UEPG, 2015. v. 2. Disponível em: <http://rh.newwp.unis.edu.br/wpcontent/uploads/sites/67/2016/06/Mudando-a-Educacao-com-MetodologiasAtivas.pdf>. Acesso em: 22 set. 2018.

MORAN, J. Educação híbrida: um conceito-chave para a educação, hoje. BACICH, L; NETO TANZIN, A. e TREVISANI, F.M. Ensino Híbrido: personalização e tecnologia da educação. Porto Alegre: Penso, 2015.

MORENO, E. L. e HEIDELMANN, S. P. Recursos instrucionais inovadores para o ensino de química. Química Nova na Escola, n. 1, p. 12-18, 2017. Disponível em: <http://qnesc.sbq.org.br/online/qnesc39_1/04-EQM-1716.pdf>. Acesso em: 04 out. 2018.

PACHECO, E. M.; PEREIRA, L. A. C. e SOBRINHO, M. D. Educação profissional e tecnológica: das escolas de aprendizes artífices aos institutos federais de educação, ciência e tecnologia. T\&C Amazônia, n. 16, p. 2-7, 2009.

PALFREY, J. e GASSER, U. Nascidos na era digital: entendendo a primeira geração de nativos digitais. Porto Alegre: Penso Editora, 2011.

PENAFORTE, G. S. e SANTOS, V. S. O ensino de química por meio de atividades experimentais: aplicação de um novo indicador natural de pH como alternativa no processo de construção do conhecimento no ensino de ácidos e bases. EDUCAmazônia, n. 2, p. 8-21, 2014. Disponível em: <https://dialnet.unirioja.es/servlet/articulo?codigo=4731867>. Acesso em: 24 nov. 2018.

TAPIA, J. A. Motivação em sala de aula. São Paulo: Edições Loyola, 1999.

VENDRUSCULO, V. e ANTUNES, M. Laboratório real e laboratório virtual: uma abordagem híbrida no ensino de conceitos de $\mathrm{pH}$ do solo no curso de agronomia. $38^{\circ}$ Encontros e Debates sobre Ensino de Química, Canoas, 2018. Disponível em: 
<http://edeq.com.br/submissao/index.php/EDEQ/38edeq/paper/view/475>. Acesso em: 25 abr. 2019.

WILEY, D. Conectando objetos de aprendizagem com a teoria de projeto instrucional: Uma definição, uma metáfora, e uma taxonomia. Disponível em: <http://penta3.ufrgs.br/midiasedu/modulo11/wiley/index.htm>. Acesso em: 24 nov. 2018.

WOLLINGER, P. Educação em Tecnologia no Ensino Fundamental: Uma Abordagem Epistemológica. Tese (Doutorado em Educação). Universidade de Brasília, Brasília, 2016. Disponível em:

<http://repositorio.unb.br/handle/10482/21328>. Acesso em: 03 set. 2018.

WOLLINGER, P. e ALLAIN, O. O fazer-saber do trabalho e sua formação.

Florianópolis: Cerfead-IFSC, 2017. 